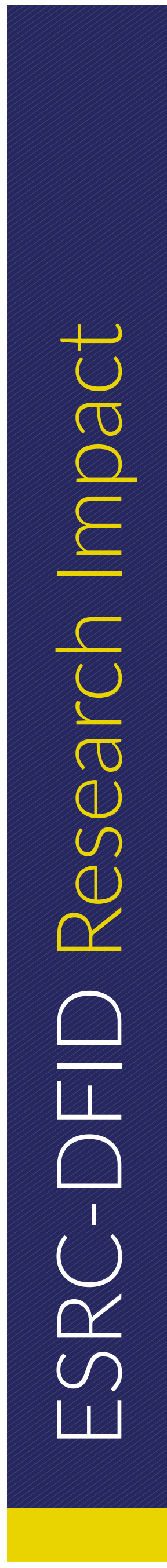

\title{
IMPROVING RURAL LIVES THROUGH THE LIBERIAN MOTORBIKE BOOM
}

Parallel to the mobile phone revolution in Africa is the lesser talked about motorbike boom. Motorbike taxis have changed the face of transport and provided employment opportunities, particularly in rural parts, in many African countries. In regions previously affected by conflict, such as Liberia, the transport sector has been a lifeline, not only providing jobs for ex-combatants but also providing much needed access to health care, schools, and markets. ${ }^{1}$

Researchers based at Swansea University recognised the benefits of this transport and looked for ways to support it. Following the Ebola crisis of 2014-15, they recognised that transforming footpaths to tracks provided a simple and affordable way to open up rural areas for motorbikes, and potentially change the lives of remote and rural communities in Liberia. Still in its early stages, this ESRC-DFID-funded project has influenced a World Bank Transport Systems consultant to push for the inclusion of this approach in Liberia's draft National Roadmap, and other donors are interested in funding similar initiatives.

\section{THE CHALLENGE}

A study in neighbouring Sierra Leone found that 65-95 per cent of passenger and freight transport takes place by motorbike taxis ${ }^{2}$ and in Liberia motorbikes are likely to have a similar share in the public transport market. But because of this taxi revolution, existing research on rural transport has quickly become outdated.

Donors often invest in 'conventional' road construction. Depending on terrain and construction standards the cost to improve $1 \mathrm{~km}$ of a standard road can vary greatly, ranging from US\$50,000 to US $\$ 200,000$. Limited budgets mean standard roads are unlikely to reach marginalised rural communities, denying people motorised access to services they need.

\section{THE RESEARCH}

Dr Krijn Peters from Swansea University and Independent Consultant Jim Clarke were already aware of the taxi boom. They wanted to see whether improvements to the tracks significantly changed the lives of rural communities in three villages in Liberia. The Ebola epidemic in West Africa demonstrated the challenges of providing health-care services to rural communities during a crisis, and appeared to support the theory that upgrading footpaths for motorbikes could significantly improve development outcomes.

The researchers knew that upgrading the footpaths in this way was relatively cheap, but without hard data on impact, relevant state actors and international donors were reluctant to allocate funds. At the heart of their three-year research project they asked whether

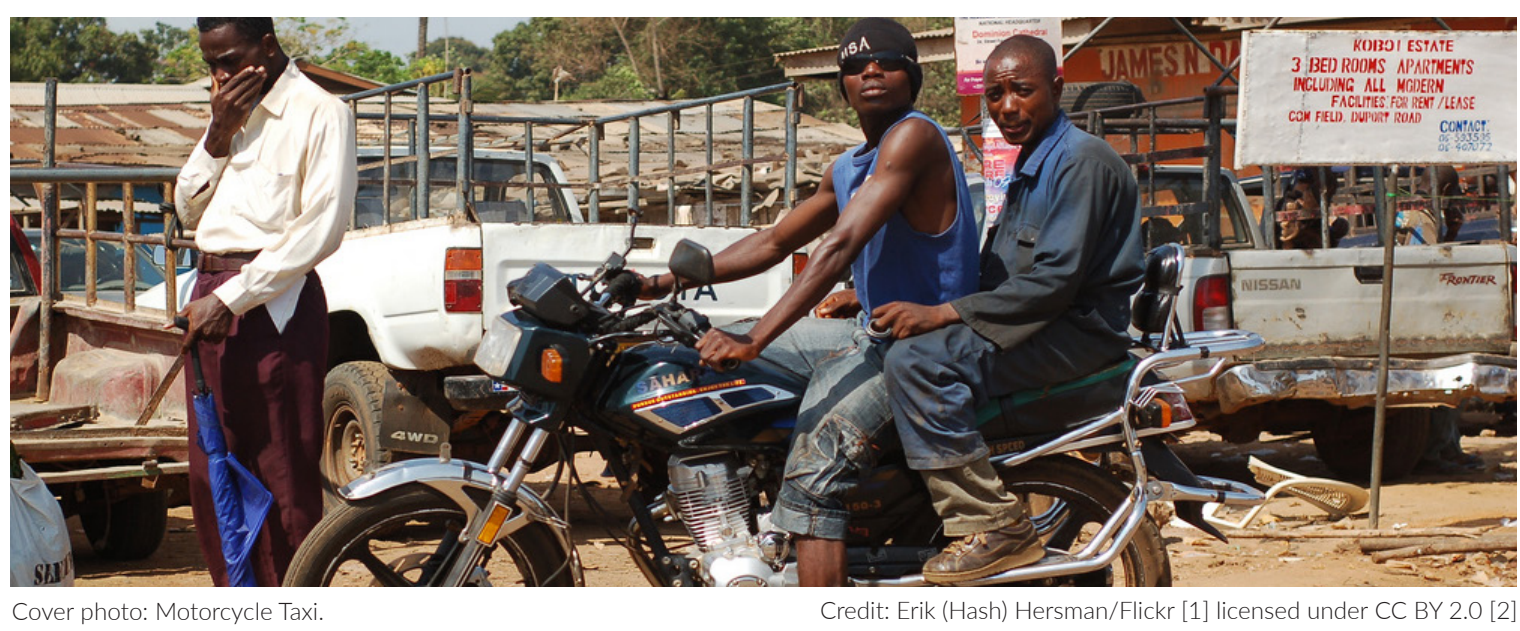

1. Jenkins, J. and Peters, K. (2016) 'Rural Connectivity in Africa: Motorcycle Track Construction', Transport 169: TR6.

2. Mustapha, A.; Peters, K. and Tunis, N. (forthcoming, 2018) Rural Transport Diagnostic Study in Sierra Leone, Final Report SLE2108A, Research for Community Access Partnership (ReCAP). 
track upgrades could be a low-cost intervention to compliment, or even be an alternative to, relatively expensive feeder road construction.

Led by Krijn, with AKA Research in Sierra Leone and Lofa Integrated Development Association (LIDA) in Liberia, the qualitative study took place in 2015, in three Liberian villages. Specifically, the researchers wanted to understand the impact that motorbikenavigable track building has on lifting farmers, and other members of the community, out of poverty. They also wanted to document the process and issues arising from community involvement in the decisionmaking and construction process.

\section{THE IMPACT}

The impact assessment is due in 2018, but the findings are already looking promising. The researchers have seen that upgrading footpaths has reduced the travelling time to markets and health facilities from a 1-3-hour walk to a short taxi ride. It also makes it easier to transport crops to markets, and secure vital income. The construction and maintenance of these tracks has used local labour and materials - providing much-needed employment to communities.

The potential to expand this idea across Africa demonstrates value for money to funders and major donors and governments, including the Department for International Development (DFID), German Development Agency (GIZ), Swedish International Development Cooperation Agency (Sida), and the Sierra Leonean government; many of which have indicated an interest in taking this idea forward in their own plans and processes.

According to World Bank Transport Systems consultant Paul Starkey, this research is set to influence the policies and actions of governments and donors alike:

There is great potential for the emulation of such policies and practices in numerous countries in sub-Saharan Africa so that many more villages can be served for the first time by motorised transport services, thus positively affecting the lives of hundreds of millions of people Paul Starkey, World Bank Transport Systems
However, this issue isn't so straightforward. Many governments in West Africa are hostile to motorbike road users as drivers are perceived to be rule breakers, making it challenging to regulate and prevent road accidents. Motorbike use was banned across Ghana in 2012, and in the capital city of Liberia, Monrovia, in 2013. However, in 2016, Krijn was invited to be a Technical Advisor to a Research for Community Access Partnership (ReCAP)/DFID-funded rural transport diagnostic study in Ghana. The subsequent recommendations are to change the universal ban on motorbike taxis in Ghana and allow them in rural areas, and this is currently with the legislators. This demonstrates the potential for this project to grow to other communities and countries in sub-Saharan Africa.

\section{FURTHER READING}

Peters, K. (2007) 'From Weapons to Wheels. Young Sierra Leonean Ex-Combatants Become Motorbike Taxi-Riders', Journal of Peace, Conflict and Development 10: 1-23

Porter, G. (2013) Transport Services and their Impact on Poverty and Growth in Rural Sub-Saharan Africa, AFCAP/ Durham University

Richards, P.; Archibald, S.; Bruce, B.; Modad, W.; Mulbah, E.; Varpilah, T. and Vincent, V. (2005) Community Cohesion in Liberia: A Post-War Rapid Social Assessment, Social Development Papers: Conflict Prevention \& Reconstruction No. 21, Washington DC: World Bank

At the end of the feeder road: assessing the impact of track construction for motorbike taxis on agrarian development in Liberia

The research team was funded by ESRC-DFID's Joint Fund for Poverty Alleviation Research, led by Dr Krijn Peters, Swansea University.

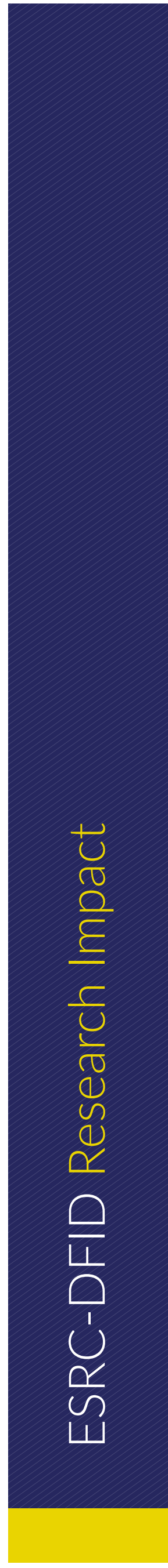

\section{CREDITS}

This impact story was written by Vivienne Benson, Institute of Development Studies in collaboration with Krijn Peters, Swansea University. Further editing was provided by James Georgalakis and Kelly Shephard, Institute of Development Studies.

\footnotetext{
influencing and engagement opportunities, and facilitate mutual learning. The Impact Initiativ
is a collaboration between the Institute of Development Studies (IDS) and the University of Cambridge's Research for Equitable Access and Learning (REAL) Centre.

Impact Initiative seeks to connect policymakers and practitioners with the world-class uptake and impact of research from: (i) the Joint Fund for Poverty Alleviation Research, an (ii) the Raising Learning Outcomes in Education Systems Programme. We seek to identify synergies between these programmes and their grant holders, support them to exploit
} 